Session 3560

\title{
Outcome Assessment and Evaluation of Engineering Education at Kuwait University
}

\author{
Andreas P. Christoforou, Mohammad D. Al-Ansary, Ahmet S. Yigit, Aziz Tayfun, \\ Adel A. Aly, Haitham Lababidi, Faridah Ali, Ibrahim S. Nashawi, \\ Mohamed Zribi \\ College of Engineering and Petroleum \\ Kuwait University \\ P.O. Box 5969, Safat 13060 \\ Kuwait
}

\begin{abstract}
The initial stages of development and implementation of assessment plans for engineering programs at Kuwait University have been completed. The plans include a structured process that translates educational objectives into measurable outcomes at the program and course levels, necessary assessment instruments, and feedback channels for corrective action. This paper presents the experience in developing such plans.
\end{abstract}

\section{Introduction}

The College of Engineering and Petroleum at Kuwait University, in line with its efforts to improve and maintain the quality of engineering education offered by its programs, initiated external evaluations conducted by the Accreditation Board for Engineering and Technology (ABET). So far, there have been three ABET evaluations of the engineering programs at the college. All the evaluated programs were found to be substantially equivalent to accredited programs with similar titles in the United States. A fourth evaluation is scheduled for the Fall of 2002. The evaluations are based on the ABET conventional criteria, also known as the Engineering Topics Criteria.

In a major shift influenced by pressure from industry and global competition, ABET has introduced the new Engineering Criteria 2000 (EC 2000) ${ }^{1}$, which address the effectiveness of engineering education programs by focusing on an assessment and evaluation process that assures the achievement of a set of educational objectives and outcomes. The new criteria provide a new basis for accrediting engineering programs in the United States, that is based on the principles of outcomes assessment and a continuous improvement process, relating educational objectives to the curriculum and to educational outcomes. Each program that seeks accreditation must have educational objectives that are consistent with the mission of the institution and are based on the needs of the program's various constituencies (e.g., students, faculty, alumni, and employers), a process that translates the educational objectives into 
educational outcomes, with an ongoing assessment that the outcomes are being measured, and evidence that the results of the assessment are being applied for further development and improvement of the program. Although the new basis is straightforward, practical implementation is not easy because of the inherent freedom in the new criteria and the established rigidity of the old criteria.

Though ABET has not yet started implementing EC2000 in the substantial equivalency evaluations, the college viewed the new criteria as an opportunity to better structure its curriculum, instruction and assessment practices. Therefore, a process has been initiated to develop comprehensive plans for each of the engineering programs. The plans include a structured process that translates educational objectives into measurable outcomes at the program and course levels, development of required assessment instruments, and identification of relevant institutional practices, which need to be aligned. This paper presents the experience in developing such plans. Preliminary results from pilot implementations are also presented.

\section{ABET Engineering Criteria 2000}

The conventional criteria were restrictive and focused on counting resources used to achieve an acceptable standard. The new ABET EC $2000^{2}$, on the other hand, address the effectiveness of engineering education programs by focusing on setting educational objectives and outcomes, and an evaluation process that assures their achievement. Eight basic level accreditation criteria comprise the EC 2000. Criteria 2 and 3 address educational objectives and outcomes assessment. Criterion 8 deals with program specific outcomes. The remaining criteria deal with the resources necessary for the program to be able to achieve its objectives.

Criteria 2 and 3 require two major feedback systems. One system focuses on educational objectives while the other focuses on the learning outcomes that the graduates need to demonstrate. The educational objectives system deals with long-term issues, and the interfaces with the program's constituencies (e.g., faculty, students, alumni and employers). The learning outcomes system deals mainly with daily issues that faculty and administrators must consider. The interface of the two systems is the requirement to demonstrate success and improvement in the program. Therefore, both criteria call for an assessment and evaluation process that measures and demonstrates the achievement of these objectives, and uses the results to improve the program.

\section{Assessment Plan Development}

One of the key elements of a successful assessment plan is a set of measurable outcomes. A process that translates educational objectives into measurable outcomes is essential. Accordingly, the assessment development guide developed at the Rose-Hulman Institute of Technology ${ }^{3}$ was used as a guideline, in addition to various reported experiences ${ }^{4-7}$, to develop the assessment plans for the different programs in the college.

\section{Program Educational Objectives}

The Educational Objectives are derived from the College mission and vision, and in accordance with the EC 2000. The educational objectives of the engineering programs are: 
1. to impart in students a sound understanding of the fundamentals of mathematics, science and engineering science, and to develop the necessary analytical skills relevant to engineering practice;

2. to foster in students the skills for effective teamwork and communication;

3. to develop in students the skills pertinent to the engineering profession such as the identification, formulation, and solution of engineering problems and design through the use of appropriate analytical, computational and experimental tools;

4. to instill in students professional and ethical responsibility, and an understanding of the impact of engineering solutions on society; and,

5. to motivate students to engage in life-long learning and knowledge of contemporary issues.

The mission statement and these objectives have been published in the "Undergraduate Bulletin" of the college and in the college web site ${ }^{8}$. These objectives were first drafted by the faculty in 1998 and revised in December 2000 based on preliminary evaluations as well as feedback from most of our constituents (i.e., students, faculty, administration, and the employers).

The process of academic decision-making involves all major constituencies and has been in place essentially since the establishment of the college, though various modifications have been made over time. Prior to 1998 the goals of all programs of college were derived from the college and the university objectives with limited involvement of constituencies at the program level. A formal process has been in existence, however, at the university and college levels, which involves all constituents. Recognizing the importance of involving the constituents at the program level, the departments also initiated External Advisory Boards, and Student Advisory Councils.

Recently, the college has established the Office of Academic Assessment. The objectives of this office are:

- to help coordinate program assessment processes;

- to develop and implement regularly-scheduled and special-purpose student, alumni, and employer surveys;

- to assist academic, administrative, and student-support units with data from assessments, and to develop or evaluate their own assessment processes; and

- to facilitate assessment training and awareness programs.

It is proposed that the objectives are evaluated every five years based on the assessment process and other inputs from all constituencies. The decision-making and evaluation process regarding various issues at the program level involves the following bodies and committees:

The External Advisory Board consists of distinguished leaders in industry, government, and academia with experience in department's activities. The board works with the department administration for review and critique to assure that the academic programs meet expected standards as well as the needs of the industry and the country at large. The board meets at least once a year on campus. They attend presentations on the state and challenges of the department and give their opinion at the meeting or later.

The Student Advisory Council consists of self-selected or nominated students, and a nonfaculty departmental representative. The mission of the council is to improve the experience of 
all department students at Kuwait University, to provide a voice for the students to the administration, and act in an advisory capacity to the department chair. The council has monthly meetings.

The Undergraduate Program Committee is a standing committee of the faculty. Its composition is such that all program areas are represented. In addition, one member coordinates assessment activities with the office of academic assessment. The committee is responsible for curriculum development and review including setting academic policies, approval of new courses, reviewing assessment information, and periodic review of the curriculum.

Teaching Area Groups (TAG) are formed based on the current teaching interests of faculty. These groups advise the Undergraduate Program Committee on various matters related to the courses assigned to a particular group. The tasks include choice of textbooks, updating of course syllabi, and the review of assessment information.

A number of other committees are involved in improving the quality of academic environment such as student advising, faculty promotion, appointment and contract renewal, scholarship, laboratory, computing facilities, budget and planning. The advising committee is responsible for advising and counseling students to ensure a healthy progression towards graduation. Faculty promotion and retention are closely linked to satisfactory performance in teaching undergraduate courses. The college has a scholarship program to ensure the programs have sufficient faculty in all curricular areas. Laboratories and computing facilities are constantly being upgraded to ensure that the students have access to state-of-the-art facilities. The budget and planning committee works closely with the whole department to ensure that adequate funds are allocated.

\section{Program Outcomes and Assessment}

The curriculum is thoroughly based on mathematics, science, engineering science, and design to fully ensure achievement of program educational objectives. The program educational objectives are used to establish both the program outcomes and specific objectives for individual courses in the program. Measurable outcomes for each course objective and the assessment methods used are given in the course syllabi for all courses offered by the programs.

An assessment process is in place to ensure the achievement of the program educational objectives. Both the curriculum and the processes that are used to ensure the achievement of program educational objectives are continuously reviewed and modified according to inputs from various constituents. Ideas to improve the program typically come from the faculty and students, and the university and college administrations. The recommendations from periodic external evaluations such as ABET visits are also considered.

The program outcomes are derived from the program educational objectives and meet the outcome requirements of ABET EC2000 Criterion 3 as well as applicable Program Criteria (ABET Criterion 8). As an example, the Mechanical Engineering Program outcomes are given below: 
1.1 Students will have the ability to develop proper mathematical models for engineering systems and to solve the mathematics analytically or numerically.

1.2 Students will be able to recognize the involvement of physics and chemistry in modeling an engineering system and to apply successfully the appropriate concepts to obtain reasonable predictive models or verify noted systems behaviors.

1.3 Students will be able to integrate concepts from mathematics and science with other knowledge to obtain reasonable predictive models or explain behaviors.

2.1 Students will be familiar with the requirements for effective leadership and will perform effectively as members of teams.

2.2 Students will communicate effectively in oral and written form.

3.1 Students will have the ability to identify, formulate, and solve engineering problems

3.2 Students will have the ability to design and conduct laboratory experiments and critically analyze and interpret experimental data.

3.3 Students will be familiar with current technology and be able to utilize state-of-the-art hardware and software in problem solving and design.

3.4 Students will be able to design, and realize both thermal and mechanical systems, components, or processes, to meet desired needs.

4.1 Students will have the ability to identify, and critically analyze ethical issues, which arise in real engineering situations.

4.2 Students will be prepared to perform under professional obligations of the codes of ethics and to adhere to the highest principles of ethical conduct during the course of employment after graduation.

4.3 Students will have the broad education necessary to be aware of their responsibilities in safety, health, welfare, and well-being of the society and the environment during the performance of their professional duties.

5.1 Students will be committed and motivated to life-long learning as a necessity for survival in the profession and will be confident in their capabilities to acquire new knowledge independently.

5.2 Students will be aware of emerging technologies and of their impact in a local and global context and get involved in analyses and discussions of contemporary issues related to society, environment, safety, and public health.

These outcomes are related to the outcome requirements of Criterion 3(a-k), and Criterion 8(1-o) as shown in Table 1. As mentioned above these outcomes are directly derived from the program educational objectives. The numbering system used clearly indicates the relationship between the program outcomes and educational objectives (e.g., Outcome 1.1 means the first outcome derived from Educational Objective 1). These program outcomes are further developed into more detailed outcomes for integration into the curriculum, and measurement. For example Outcome 5.1 that addresses life-long learning and self-reliance is developed into the following six specific outcomes:

Mechanical Engineering graduates will be committed to

5.1.1 seek intellectual experiences for personal and professional development,

5.1.2 appreciate the relationship between basic knowledge, technological advances, and human needs,

5.1.3 life-long learning as a necessity for professional development and survival. 
5.1.4 read and comprehend technical and other materials, and acquire new knowledge independently,

5.1.5 conduct a literature survey on a given topic,

5.1.6 use the library facilities, the World Wide Web, and educational software (encyclopedias, handbooks, and technical journals on CDs).

The first three indicate attitude changes in students. Sufficient opportunities are provided to facilitate development of positive attitudes in students during their course of study, through involvement in professional societies and design projects. Evidences for the realization of the outcomes are gathered through surveys (exit, faculty, alumni and employer). The last three indicate specific performances, which can be measured during coursework by the instructors.

All the program outcomes are embedded into the curriculum through course objectives and outcomes. The faculty have described how each of the course objectives is related to the program outcome requirements, as well as the outcome requirements of Criterion 3 and 8 . In addition, the faculty indicated to what extent specific courses fulfill the outcome requirements of EC2000 as shown in Table 2 for the Mechanical Engineering curriculum. Additional information can be found in the course syllabi'.

Table 1: The relationship between program outcomes and ABET requirements

\begin{tabular}{|c|c|c|c|c|c|c|c|c|c|c|c|c|c|c|c|}
\hline \multirow[t]{3}{*}{ Program Outcomes } & \multicolumn{15}{|c|}{ ABET Outcomes } \\
\hline & \multicolumn{11}{|c|}{ Criterion 3} & \multicolumn{4}{|c|}{ Criterion 8} \\
\hline & a & b & c & d & e & f & g & h & i & $\mathbf{j}$ & $\mathbf{k}$ & 1 & $\mathbf{m}$ & n & 0 \\
\hline 1.1 & $\mathbf{X}$ & & & & & & & & & & & $\mathbf{X}$ & & $\mathbf{X}$ & \\
\hline 1.2 & $\mathbf{X}$ & & & & & & & & & & & & $\mathbf{X}$ & & \\
\hline 1.3 & $\mathbf{X}$ & & & & & & & & & & & $\mathbf{X}$ & $\mathbf{X}$ & $\mathbf{X}$ & \\
\hline 2.1 & & & & $\mathbf{X}$ & & & & & & & & & & & \\
\hline 2.2 & & . & & $\mathbf{X}$ & & & $\mathbf{X}$ & & & & & & & & \\
\hline 3.1 & & & & & $\mathbf{X}$ & & & & & & $\mathbf{X}$ & & & & \\
\hline 3.2 & & $\mathbf{X}$ & & & & & & & & & & & & & \\
\hline 3.3 & & & & & & & & & & & $\mathbf{X}$ & & & & \\
\hline 3.4 & & & $\mathbf{X}$ & & & & & & & & & & & & $\mathbf{X}$ \\
\hline 4.1 & & & & & & $\mathbf{X}$ & & & & & & & & & \\
\hline 4.2 & & & & & & $\mathbf{X}$ & & & & & & & & & \\
\hline 4.3 & & & & & & & & $\mathbf{X}$ & & & & & & & \\
\hline 5.1 & & & & & & & & & $\mathbf{X}$ & & & & & & \\
\hline 5.2 & & & & & & & & & & $\mathbf{X}$ & & & & & \\
\hline
\end{tabular}

The assessment process involves both course level and program level assessment practices. As indicated in Table 2, each course in the curriculum addresses some of the ABET specified outcomes. The level at which these outcomes are addressed is specified as High $(\mathrm{H})$, Medium (M) and Low (L). A designation of $\mathrm{H}$ for an outcome in a course indicates that demonstrating this knowledge or skill is critical for the student to perform successfully in the course, and it is one of the most important outcomes of the course. If demonstrating this knowledge or skill has considerable impact on the overall performance of the student a designation of $\mathrm{M}$ is assigned. A designation of $\mathrm{L}$ indicates that demonstrating this knowledge or skill has only 
minor impact on the overall performance of the student. These designations are assigned by a group of faculty who teach the course.

Table 2: The relationship between the courses in the curriculum and ABET requirements

\begin{tabular}{|c|c|c|c|c|c|c|c|c|c|c|c|c|c|c|c|}
\hline \multirow[t]{2}{*}{ Courses } & \multicolumn{15}{|c|}{ ABET Outcomes } \\
\hline & \multicolumn{11}{|c|}{ Criterion 3} & \multicolumn{4}{|c|}{ Criterion 8} \\
\hline General Education Requirements & $\mathbf{a}$ & $\mathbf{b}$ & $\mathbf{c}$ & d & e & $f$ & $\mathrm{~g}$ & $\mathbf{h}$ & $\mathbf{i}$ & $\mathbf{j}$ & $\mathbf{k}$ & & $\mathbf{m}$ & $n$ & 0 \\
\hline Humanities and Social Science electives ( 12 credits) & & & & & & & & $\mathrm{H}$ & & $\mathrm{H}$ & & & & & \\
\hline English language courses ( 6 credits) & & & & & & & $\mathrm{H}$ & & & & & & & & \\
\hline Math and science courses and labs (27 credits) & $\overline{\mathrm{H}}$ & & & & & & & & & & & $\mathrm{H}$ & $\mathrm{H}$ & $\mathrm{H}$ & \\
\hline Basic Engineering Requirements & $\mathbf{a}$ & b & c & d & $\mathbf{e}$ & $\mathbf{f}$ & $\mathbf{g}$ & $\mathbf{h}$ & $\mathbf{i}$ & $\mathbf{j}$ & $\mathbf{k}$ & l & $\mathbf{m}$ & $\mathbf{n}$ & $\mathbf{0}$ \\
\hline Engineering Workshop & $\mathrm{L}$ & & & & & $\mathrm{H}$ & & $\mathrm{M}$ & & & $\mathrm{H}$ & & & & \\
\hline Engineering Graphics & $\mathrm{L}$ & & & & & & $\mid \mathrm{H}$ & & & & $\mathrm{H}$ & & & & $\mathrm{H}$ \\
\hline Computer Programming For Engineers & & & & & $\mathrm{L}$ & & & & & & $\mathrm{H}$ & & & & \\
\hline Statics & $\mathrm{H}$ & & & & $\mathrm{H}$ & & & & & & $\mathrm{L}$ & & & & \\
\hline Dynamics & $\mathrm{H}$ & & & & $\mathrm{H}$ & & & & & & $\mathrm{L}$ & $\mathrm{H}$ & $\mathrm{H}$ & & \\
\hline Strength of Materials & $\mathrm{H}$ & & $\mathrm{M}$ & & $\mathrm{H}$ & & & & & & & & & & \\
\hline Electrical Engineering Fundamentals & $\bar{H}$ & & & & $\mathrm{H}$ & & & & & & $\mathrm{M}$ & $\mathrm{H}$ & $\mathrm{H}$ & & \\
\hline Electrical Engineering Fundamentals Laboratory & $\mathrm{M}$ & $\mathrm{H}$ & & & $\mathrm{M}$ & $\mathrm{L}$ & $\mathrm{M}$ & & & & $M$ & & & & \\
\hline Engineering Thermodynamics & $\mathrm{H}$ & & & & $\mathrm{H}$ & M & & M & & & $\mathrm{M}$ & $\mathrm{L}$ & & & \\
\hline Engineering Econom y & $\mathrm{M}$ & & $\mathrm{M}$ & & $\mathrm{M}$ & & & $\mathrm{H}$ & $\mathrm{M}$ & $\mathrm{H}$ & $\mathrm{M}$ & & & & \\
\hline Engineering Probability And Statistics & $\mathrm{H}$ & & & & $\mathrm{H}$ & & & $\mathrm{M}$ & $\mathrm{M}$ & $\mathrm{M}$ & $\bar{M}$ & & & $\mathrm{H}$ & \\
\hline Numerical Methods In Engineering & $\mathrm{H}$ & & & & $\mathrm{M}$ & & & & & & \begin{tabular}{|ll}
$\mathrm{H}$ \\
$\mathrm{H}$
\end{tabular} & & & & \\
\hline Mechanical Engineering Requirements & $\mathbf{a}$ & b & $\mathbf{c}$ & d & $\mathbf{e}$ & $\mathbf{f}$ & $\mathrm{g}$ & $\mathbf{h}$ & $\mathbf{i}$ & $\mathbf{j}$ & $\mathbf{k}$ & 1 & $\underline{m}$ & $\underline{n}$ & $\mathbf{0}$ \\
\hline Materials Science And Metallurgy I & $\mathrm{H}$ & $\mathrm{M}$ & $\mathrm{L}$ & $\mathrm{L}$ & $\mathrm{M}$ & & $\mathrm{L}$ & $\mathrm{L}$ & $\mathrm{L}$ & $\mathrm{M}$ & $\mathrm{L}$ & & & & $\mathrm{M}$ \\
\hline Introduction To Design & $\mathrm{M}$ & & $\mathrm{H}$ & $\mathrm{H}$ & $\mathrm{H}$ & $\mathrm{H}$ & $\mathrm{H}$ & $\mathrm{H}$ & $\mathrm{M}$ & $\mathrm{M}$ & $\mathrm{H}$ & & & & $\mathrm{M}$ \\
\hline Theory Of Machines & $\overline{\mathrm{H}}$ & & $\mathrm{M}$ & $\mathrm{L}$ & $\mathrm{H}$ & $\mathrm{L}$ & $\bar{M}$ & $\bar{M}$ & $\mathrm{M}$ & $\mathrm{L}$ & $\bar{M}$ & $\mathrm{~L}$ & & $\bar{M}$ & $\overline{\mathrm{I}}$ \\
\hline System Dynamics & $\mathrm{H}$ & & $\mathrm{L}$ & $\mathrm{L}$ & $\mathrm{H}$ & $\mathrm{M}$ & $\mathrm{M}$ & $\mathrm{L}$ & $\mathrm{L}$ & $\mathrm{L}$ & $\mathrm{H}$ & $\mathrm{H}$ & $\mathrm{H}$ & $\mathrm{M}$ & $\mathrm{M}$ \\
\hline Engineering Thermodynamics II & $\mathrm{H}$ & & $\mathrm{H}$ & & $\mathrm{H}$ & & $\mathrm{M}$ & $\mathrm{M}$ & $\mathrm{M}$ & & & $\mathrm{L}$ & & $\mathrm{L}$ & \\
\hline Fluid Mechanics & $\mathrm{H}$ & & $\mathrm{L}$ & $\mathrm{L}$ & $\mathrm{H}$ & $\mathrm{L}$ & $\mathrm{M}$ & $\mathrm{M}$ & $\mathrm{L}$ & $\mathrm{L}$ & $\mathrm{M}$ & $\mathrm{M}$ & $\mathrm{M}$ & & $\bar{H}$ \\
\hline Mechanical Design I & $\mathrm{M}$ & & $\mathrm{M}$ & $\mathrm{M}$ & $\mathrm{H}$ & $\mathrm{L}$ & $\mathrm{H}$ & $\mathrm{M}$ & $\mathrm{M}$ & $\mathrm{M}$ & $\mathrm{H}$ & & & & $\mathrm{M}$ \\
\hline Manufacturing Processes & $\mathrm{L}$ & & $\mathrm{H}$ & $\mathrm{H}$ & $\mathrm{H}$ & $\mathrm{M}$ & $\mathrm{H}$ & $\mathrm{H}$ & $\mathrm{M}$ & $\mathrm{M}$ & $\mathrm{H}$ & $\mathrm{L}$ & & & $\mathrm{M}$ \\
\hline Engineering Fundamentals Laboratory & $\mathrm{M}$ & $\mathrm{H}$ & $\mathrm{M}$ & $\mathrm{H}$ & $\mathrm{M}$ & & $\mathrm{H}$ & & & & $\mathrm{M}$ & & & $\mathrm{H}$ & $\mathrm{H}$ \\
\hline Mechanical Vibrations & $\overline{\mathrm{H}}$ & & $\mathrm{M}$ & & $\mathrm{H}$ & $\bar{M}$ & $\mathrm{M}$ & $\bar{M}$ & $\mathrm{M}$ & $\mathrm{M}$ & $\bar{H}$ & $\mathrm{H}$ & $\mathrm{H}$ & $\mathrm{H}$ & $\mathrm{M}$ \\
\hline Control Of Mechanical Systems & $\mathrm{H}$ & & $\mathrm{H}$ & $\mathrm{M}$ & $\mathrm{H}$ & M & $\mathrm{M}$ & & $\mathrm{M}$ & $\mathrm{L}$ & $\mathrm{H}$ & $\mathrm{H}$ & $\mathrm{H}$ & $\mathrm{M}$ & $\mathrm{I} \mid \mathrm{M}$ \\
\hline Heat Transfer & $\mathrm{H}$ & & $\mathrm{M}$ & $\mathrm{H}$ & $\mathrm{H}$ & $\mathrm{M}$ & $\mathrm{H}$ & $\mathrm{M}$ & $\mathrm{L}$ & $\mathrm{L}$ & $\mathrm{H}$ & $\mathrm{M}$ & $\mathrm{H}$ & $\mathrm{L}$ & \\
\hline Refrigeration And Air Conditioning & $\mathrm{M}$ & & $\mathrm{H}$ & $\mathrm{M}$ & & & & & $\mathrm{M}$ & $\mathrm{L}$ & $\mathrm{M}$ & $\mathrm{M}$ & & & $\mathrm{M}$ \\
\hline Mechanical Design II & $\overline{\mathrm{H}}$ & & $\mathrm{H}$ & $\mathrm{M}$ & $\mathrm{H}$ & $\mathrm{H}$ & $\mathrm{M}$ & $\bar{M}$ & $\mathrm{M}$ & $\mathrm{M}$ & $\bar{M}$ & $\bar{M}$ & & $\mathrm{~L}$ & $\mathrm{M}$ \\
\hline Computer Aided Design & $\mathrm{H}$ & & $\mathrm{H}$ & $\mathrm{H}$ & $\mathrm{H}$ & $\mathrm{H}$ & $\mathrm{H}$ & $\mathrm{M}$ & $\mathrm{M}$ & $\mathrm{M}$ & $\mathrm{H}$ & & & & $\mathrm{H}$ \\
\hline Engineering Design & $\mathrm{H}$ & $\mathrm{M}$ & $\mathrm{H}$ & $\mathrm{H}$ & $\mathrm{H}$ & $\mathrm{H}$ & $\mathrm{H}$ & $\mathrm{H}$ & $\mathrm{H}$ & $\mathrm{H}$ & $\mathrm{H}$ & $\mathrm{M}$ & $\mathrm{H}$ & $\mathrm{H}$ & $\mathrm{M}$ \\
\hline Thermal Science Laboratory I & $\mathrm{H}$ & $\mathrm{H}$ & $\mathrm{M}$ & $\mathrm{M}$ & $\mathrm{M}$ & & $\mathrm{M}$ & & & & $\bar{M}$ & & & & $\mathrm{M}$ \\
\hline Dynamics Of Machines And Mechanical Vib ration Lab. & $\mathrm{M}$ & $\mathrm{H}$ & M & $\mathrm{M}$ & $\mathrm{M}$ & $\mathrm{M}$ & $\mathrm{H}$ & $\mathrm{M}$ & $\mathrm{M}$ & $\mathrm{M}$ & $\mathrm{H}$ & & & $\mathrm{M}$ & $\mathrm{I} \mid \mathrm{M}$ \\
\hline Thermal Science Laboratory II & $\mathrm{H}$ & $\mathrm{H}$ & $\mathrm{M}$ & $\mathrm{M}$ & $\mathrm{M}$ & & $\mathrm{M}$ & & & & $\mathrm{M}$ & & & $\mathrm{M}$ & $\mathrm{M}$ \\
\hline Control Of Mechanical Systems Laboratory & $\mathrm{H}$ & $\mathrm{H}$ & $\mathrm{L}$ & $\mathrm{L}$ & $M$ & $\mathrm{H}$ & $\mathrm{H}$ & $\mathrm{L}$ & $\mathrm{L}$ & $\mathrm{L}$ & $\mathrm{H}$ & $\mathrm{H}$ & $\mathrm{M}$ & $\mathrm{H}$ & $\mathrm{M}$ \\
\hline Mechanical Engineering Electives & $\mathbf{a}$ & b & c & d & $\mathbf{e}$ & $\mathbf{f}$ & g & h & $\mathbf{i}$ & $\mathbf{j}$ & $\mathbf{k}$ & l & m & $\mathbf{n}$ & $\mathbf{0}$ \\
\hline Technical electives (15 credits) & $\mathrm{H}$ & $\mathrm{L}$ & $\mathrm{H}$ & $\mid \mathrm{L}$ & |H & $\mathrm{H}$ & $\mathrm{M}$ & $\mathrm{M}$ & $\mathrm{M}$ & $|\mathrm{M}|$ & $\mathrm{H}$ & & & & $\mathrm{I} \mid \mathrm{M}$ \\
\hline
\end{tabular}

At the course level, the individual instructors perform the initial assessment. The main assessment tool used is the Instructor Class Evaluation Form. This form reports the grade 
distribution as well as the assessment of program outcomes served by the course. Depending on the nature of the course, in addition to sample student works submitted as evidences, instructors use specific tools, such as team evaluation form, written report evaluation form, etc. to document their assessment. The teaching area groups perform the second assessment at the course level. Each group evaluates the assessment results for the courses in their area to ensure the achievement of course objectives. In addition, they provide feedback to the undergraduate program committee for program level assessment. The committee evaluates the assessment results and recommendations of the teaching area groups as well as other assessment results (e.g., exit, alumni, employer surveys) to ensure that the graduates are achieving the program outcomes.

The assessment process established in the departments and the college works in a continuous improvement cycle. The undergraduate program committee in cooperation with the department chair reviews the results of the assessment and compares them to the established criteria. Based on the analysis one of the following actions are taken ${ }^{10}$ :

The existing criterion is met: In this case, the criterion is reviewed and the results reported to the faculty and the college through the Office of Academic Assessment.

The existing criterion is not met: In this case an investigation is carried to determine the causes. In some cases, an assessment tool or method used to measure an outcome may need improvement. If this is the case, the undergraduate program committee recommends the appropriate changes to address the shortcomings. In certain cases, the criterion itself may not be appropriate and needs revision. In other cases, there may be deficiencies or shortcomings in the curriculum, practices or policies. For these cases, the undergraduate program committee studies the problem, and recommends possible actions, which may include curriculum revision, policy changes, and communication to appropriate committees within the department or to the Office of Academic Assessment for further action.

\section{Initial Assessment Results}

All early indicators show that the initial efforts have been fruitful. Although it is early to determine how these efforts would lead to improvement of the quality of education, the initial reactions of the faculty, students and the employers who were involved in the process are very positive. The course level assessment process, which has been in place for only two semesters, has already resulted in useful recommendations regarding the content, pre-requisites, and teaching methodologies of certain courses.

In order to provide awareness and training for outcome-based course assessment, the Office of Academic Assessment organized and offered workshops in May, October and November 2001. The objectives of these workshops were:

- to introduce the paradigm of outcome-based assessment;

- to instill the culture of assessment in faculty; and

- to present and explain the assessment tools developed or adopted in the college.

Overall all the workshops were very successful. Most of the attendees expressed their satisfaction both formally through the workshop evaluations and informally through discussions during and after the workshop, as evidenced by their enthusiasm and motivation. This helped create a dynamic and interactive environment where everybody participated in discussions and hands-on activities. Most of the attendees expressed a desire to use the 
techniques presented during the workshops. A significant number of attendees also expressed interest to learn more on the subject. It is expected that the faculty who participated in these workshops will be very instrumental in effective implementation of assessment.

The Office of Academic Assessment also carried out an employer survey, and subsequently organized an employer gathering to obtain feedback regarding the industry needs as well as their assessment of the quality of engineering graduates. The response rate for the employer survey was good (240 out of 642). The respondents rated the quality of recent engineering graduates with respect to various outcomes using a scale of very strong, strong, average, below average, and poor. While the college graduates were rated to be above average in all specified outcomes, the survey indicated that the employers are not very much satisfied with the level of preparation of graduates in communication skills. Also for some programs, design is identified to be an area that needs improvement.

The gathering was organized in Fall 2001. The objectives were:

- to thank employers for their participation in the employer assessment of the college graduates;

- to present the results of the last survey;

- to hear views and concerns regarding engineering education in the college; and

- to establish a continuous feedback channel between the college and the industry.

A total of 48 employers or employer representatives from public and private sectors attended the gathering. In addition, the college administration (i.e., the dean and vice-deans, department chairs and unit directors) and the chairs of program undergraduate committees, and program assessment liaisons were present. Overall, the meeting was very successful. The feedback received during and after the meeting was very valuable. There was consensus about holding this type of gatherings periodically. It gave the college an opportunity to communicate its efforts to improve the quality of engineering education. Also, the employers were able to communicate their views directly to the college administration. It proved to be very convenient and effective way of involving constituencies in the assessment process.

Also, a needs survey was carried out during and after the employer gathering. The objectives of the survey were:

- to obtain feedback from the employers on educational outcomes, and to determine their priorities;

- to obtain a profile of employers; and

- to establish a database to be used for future surveys.

The needs survey is arranged in four sections. The first section deals with the importance of some curricular subjects relative to the needs of employers. The other sections are about educational outcomes clustered in three groups. Most of the curricular subjects were found to be important by the majority of the respondents (except humanities and social sciences). In particular, $43 \%$ thought that humanities and social sciences are somewhat important. On the other hand, $90 \%$ of the respondents rated engineering science and computer science as important.

All the outcomes were rated as important by most of the respondents. Some of these outcomes were rated as very important or extremely important by more than $80 \%$ of the 
respondents (problem solving: 81\%, professional and ethical responsibility: 95\%, oral communication: $81 \%$, written communication: $95 \%$, life-long learning: $81 \%$, and using modern tools: $81 \%$ ). These results show that the program educational objectives developed earlier are consistent with the needs of the employers.

The employers' comments, which were collected through the open-ended section of the survey, are consistent with the ratings mentioned above. Many respondents emphasized the utility of practical training. Also, an increased cooperation between the employers and the college was highly recommended.

Finally exit surveys of graduating students have been conducted for the last two semesters. According to the initial plan, every program was responsible for carrying out their own exit surveys with separate instruments. For example, ratings of graduating seniors from the Mechanical Engineering Program for all outcomes were higher than $70 \%$. The results correlated well with that of the employer assessment. Total scores from the exit and employer surveys were very close. For certain questions the exit survey scores were relatively higher. These items are: problem solving, engineering design, oral and written communication, and experimental skills. This is to be expected since the students are in a better position to appreciate recent emphasis on these skills. For teamwork, the exit survey rating was lower than that of the employer assessment. Though the results indicate that the graduating students are generally satisfied with respect to their preparation, the following items were rated somewhat lower than the rest of the skills, and therefore may warrant special attention: teamwork, impact of technology on society, self development, modern tools, and environmental awareness. It appears that the students are aware of the importance of these skills and attributes and want the program to have more emphasis on these issues. It also became clear that there is a need to unify the assessment instruments across programs to ease data management and facilitate correlation with other surveys such as alumni and employer surveys.

\section{Summary and Conclusions}

The initial stages of the outcome assessment process have been completed. A structured process that includes development of measurable outcomes, assessment tools, and feedback mechanisms is in place for all engineering programs. The key element in the success of the initial effort lies in the full cooperation and involvement of the faculty and administration, as well as students and employers.

Plans are currently underway to review and evaluate the available assessment results. It is anticipated that the curriculum and assessment plans will be revised accordingly. Existing assessment tools are currently being unified for ease of data management and correlation. Assessment is being conducted at the course, program, and college levels. In the overall process,

- students are informed of the outcomes;

- course and project evaluations are based on outcomes;

- students write and reflect on their progress towards outcomes in various courses;

- students are advised on progress toward outcomes;

- students' progress toward outcomes is documented; and

- passing courses is based on satisfying outcomes as well. 
Evaluation methods that are/could be applied to assess achievement of outcomes are:

- criterion based grading;

- student portfolios;

- homework and exams,

- projects from classes,

- students' reflection on their learning;

- entry and exit surveys/interviews; and

- standard tests (e.g., Fundamentals of Engineering exam).

It is clear that assessment is multilevel, multidirectional and with many interfaces, and thus very challenging ${ }^{11}$. Therefore, maintaining and improving cooperation and participation of all concerned parties is of paramount importance at this stage. The willingness to make and apply decisions, adapt and change the curriculum for continuous improvement is the guiding principle. In doing so, care is taken not to overwhelm the faculty and the students. Finally, institutional practices beyond the college level (e.g., admissions, teaching evaluations, new course approval mechanisms, faculty orientation, rewards system, course load, promotion practices, tenure and contract system, cross- college linkages, etc.) must be reviewed for missalignments that may hinder an effective assessment program ${ }^{11}$.

\section{Acknowledgements}

The authors are the team members of the Project EM03-99, funded by Kuwait University Research Administration. They also act as assessment coordinators in their programs. The authors would also like to acknowledge the support of the Dean of the College of Engineering and Petroleum, and the Office of Academic Assessment.

\section{Bibliography}

1. Phillips, W.M., Peterson, G.D., and Aberle, K.B. (2000), "Quality Assurance for Engineering Education in a Changing World," International Journal of Engineering Education, Vol. 16, No. 2, pp. 97-103.

2. Engineering Accreditation Commission (1997), Engineering Criteria 2000, Third Edition, Accreditation Board for Engineering and Technology, Inc., Baltimore, MD.

3. Rogers, G.M., and Sando, J.K. (1996), Stepping Ahead : An Assessment Plan Development Guide , RoseHulman Institute of Technology, Foundation Coalition.

4. Georgia Institute of Technology (1997), Program Self-Study for Mechanical Engineering , http://www.me.gatech.edu/me/academics/abet/metoc.htm

5. McGourty, J., Sebastian, C., and Swart, W. (1997), "Performance Measurement and Continuous Improvement of Undergraduate Engineering Education Systems," Proceedings of the 27th Frontiers in Education Conference, Pittsburgh, PA, pp. 1294 -1301.

6. Besterfield-Sacre, M., Shuman, L.J., Wolfe, H., Atman, C.J., McGourty, J., Miller, R.L., Olds, B.M., and Rogers, G.M. (2000), "Defining the Outcomes: A Framework for EC 2000,", IEEE Transactions on Education, Vol. 43, No. 2, pp.100-110.

7. North Carolina State University, (2000), College of Engineering Assessment Database, http://www.engr.ncsu.edu/assessment/coe2.html

8. Kuwait University (2000), College of Engineering and Petroleum, Office of Academic Assessment, Assessment Page, http://www.eng.kuniv.edu.kw/ oaa/

9. Kuwait University (2001), Mechanical Engineering Assessment Plan

10. Clemson University (1999), Self Study for Department of Mechanical Engineering , http://www.ces.clemson.edu/me/abetpdf/selftstudy.html 
11. Mcgourty, J. (1998), "Strategies for Developing, Implementing, and Institutionalizing a Comprehensive Assessment Process for Engineering Edu cation", Proceedings of the 28th Frontiers in Education Conference, Tempe, AZ, p 117-121.

\section{ANDREAS P. CHRISTOFOROU}

Andreas P. Christoforou is an Associate Professor at the Department of Mechanical Engineering, Kuwait University. He received a Ph.D. in Mechanical Engineering from the University of Utah. He was the chairman of department and college outcome assessment committees during the early development of assessment plans. In addition to engineering education, his research interests include impact a nd damage of composite structures.

\section{MOHAMMED D. AL-ANSARY}

Mohammed D. Al-Ansary is the Vice-Dean for Research and Academic Affairs at the College of Engineering and Petroleum, Kuwait University. He is also a Professor at the Department of Mechanical Engine ering. He received a Ph.D. in Mechanical Engineering from the Ohio State University. His research interests include vibrations and fracture mechanics.

\section{AHMET S. YIGIT}

Ahmet S. Yigit is the Director of the Office of Academic Assessment at the College of Eng ineering and Petroleum, Kuwait University. He is also a Professor at the Department of Mechanical Engineering. He received a Ph.D. in Mechanical Engineering from the University of Michigan. His research interests include dynamics and control of flexible sy stems, impact, and engineering education.

\section{AZIZ TAYFUN}

Aziz Tayfun is a Professor at the Department of Civil Engineering. He received a Ph.D. in Civil Engineering from the University of Delaware. He served as a coordinator for the outcome assessment activi ties at the Civil Engineering Department. He has also been a member of the College Outcome Assessment Committee. His research interests include sea waves, wave statistics and wave -induced processes in the oceans.

ADEL A. ALY

Adel A. Aly is a Professor at the Department of Industrial and Management Systems Engineering, Kuwait University. He received his Ph.D. from Virginia Polytechnic Institute and State University. He also serves as Advisor to the Vice-President for Academic Affairs. His research interes ts include quality assurance, optimization and productivity analysis, economics and cost estimation, and decision -making.

\section{HAITHAM LABABIDI}

Haitham Lababidi is an Associate Professor at the Department of Chemical Engineering, Kuwait University. He received his Ph.D. from Leeds University, U.K. He is the chairman of the Chemical Engineering Undergraduate Program Committee. His research interests include process system engineering and artificial intelligence.

\section{FARIDAH ALI}

Faridah Ali is an Assistant Professor in the Department of Computer Engineering, Kuwait University. She received her Ph.D. degree from Virginia Polytechnic Institute and State University. She is the Coordinator of the Computer Engineering Undergraduate Program Committee. Her research intere sts include hardware/software co-design of computer systems.

\section{IBRAHIM S. NASHAWI}

Ibrahim S. Nashawi is an Associate Professor at the Department of Petroleum Engineering, Kuwait University. He received a Ph.D. in Petroleum Engineering from Louisiana Tech U niversity. His research interests include well test analysis, fluid flow in the wellbore, and neural network and expert systems in petroleum engineering .

\section{MOHAMED ZRIBI}

Mohamed Zribi is an Associate Professor at the Department of Electrical Engineering, K uwait University. He received his Ph.D. in Electrical Engineering from Purdue University. His research interests include control of nonlinear systems, robotics, control of time delay systems, and control applications. 